\title{
O GÊNERO AUTO-AJUDA E O PÚBLICO LEITOR ADOLESCENTE
}

\section{Carla Callegaro Corrêa Kader}

\section{RESUMO}

Em meio à falta de embasamento científico e no enfoque excessivo na conquista de bens materiais e na competitividade, a crise da modernidade estimula interesse pela busca interior. Com base nesta afirmação o presente trabalho busca verificar como os alunos de uma escola católica de Santa Maria partilham o discurso de auto-ajuda ou fazem uso de sua literatura. Para que isso fosse possível aplicou-se um questionário com perguntas fechadas para análise dos dados com objetivo de se traçar um perfil deste público-leitor adolescente.

\section{O GÊNERO AUTO-AJUDA}

$\mathrm{Na}$ última década a procura por livros de auto-ajuda aumentou entre os brasileiros. Diversos autores surgiram escrevendo manuais e obras que pregam a realização pessoal, concretização de sonhos, cura de doenças, dicas para atrair o ser amado, como ficar rico, entre outros. Entre os autores mais requisitados do gênero, estão Roberto Chinyashiki, Lauro Trevisan e Paulo Coelho. Mas o que estaria levando as pessoas a buscarem a auto-ajuda? No meio acadêmico e entre os intelectuais, uma das explicações plausíveis para o fenômeno seria a situação política e social do país, ou seja, o clima de instabilidade econômica e social que por conseqüência levaria o indivíduo a um estado de insegurança e instabilidade emocional. E o público leitor adolescente? O que o levaria a procurar a literatura de auto-ajuda? Por que este tipo de linguagem seria procurada por um público leitor tão jovem e sem grandes preocupações mundanas?

Este estudo visa apresentar algumas representações em relação à leitura de auto-ajuda de alunos de ensino médio de uma escola particular de Santa Maria através da análise de um questionário com perguntas fechadas.

\section{AUTO-AJUDA NA HISTÓRIA}

As mudanças comportamentais do homem na sociedade começaram a partir da Renascença. Até então as sociedades tradicionais eram sustentadas em prol do coletivo. Assim o indivíduo era levado a tolher seus impulsos de independência ou canalizá-los para as tarefas comunitárias. Isso mudou na cultura moderna. O homem 
foi levado á idéia de auto-realização. Nesse contexto, a literatura de auto-ajuda vem pregar ao homem a necessidade de expressar-se, ter convicção e fé de que possui potencial para conquistar tudo e sobressair-se entre os demais. O termo auto-ajuda surgiu através do médico escocês Samuel Smile. Em 1859, Smile escreveu "SelfHelp" (ajuda-te). O livro defendia que o homem é o agente ativo do seu próprio bemestar e do seu êxito no mundo. A obra foi publicada em mais de oito línguas e o termo virou gênero literário, despertando o interesse de outros escritores. Mais tarde na década de 80 surge a chamada neurolingüística, apresentando a proposta de dirigir, ou programar, o cérebro de uma forma favorável para se conseguir os resultados desejados. Na prática, pregava-se o mesmo que Smile (1859) só que através de uma abordagem científica.

\section{IDEOLOGIA EM COGNIÇÃO, SOCIEDADE E DISCURSO}

A definição cognitiva de ideologia é dada em termos das cognições sociais que são partilhadas pelos membros de um grupo. A dimensão social explica que tipo de grupos, as relações entre grupos e as instituições que estão envolvidas no seu desenvolvimento e na sua reprodução. $\mathrm{E}$ a dimensão do discurso explica como as ideologias influenciam nossos textos diários e nossas conversas, como entendemos o discurso, e como este está envolvido na reprodução da ideologia na sociedade. Segundo Van Dijk (2002) os membros de um grupo que partilham ideologias, apresentam idéias gerais como base de suas crenças mais específicas sobre o mundo e estas guiam sua interpretação dos eventos e monitoram suas práticas sociais.

As práticas sociais cruciais influenciadas pelas ideologias são a linguagem e o discurso, que, por sua vez, também influenciam como nós as adquirimos, as aprendemos ou as mudamos. Muito do nosso discurso, especialmente quando falamos como membros de um grupo, expressam opiniões baseadas em alguma ideologia. Nós aprendemos grande parte das nossas idéias lendo ou ouvindo os membros de um grupo, começando por nossos pais e as pessoas com as quais convivemos. Mais tarde aprendemos ideologias assistindo televisão, lendo livros e textos na escola, nas propagandas e anúncios, nos jornais, romances ou participando de conversas cotidianas com amigos e colegas. Em nossos textos diários, redações 
e em nossas conversas mais banais expressamos nossa forma de ver e ler o mundo e desta forma reproduzimos e partilhamos ideologia.

\section{ANÁLISE DOS DADOS DA PESQUISA}

Neste trabalho verificaremos como os alunos de uma escola católica de Santa Maria partilham o discurso de auto-ajuda ou fazem uso de sua literatura. Para que fosse possível estabelecer um perfil ou traço característico do público leitor de autoajuda adolescente e das possíveis razões que o fazem buscar o gênero auto-ajuda, foi aplicado um questionário com treze perguntas objetivas a um grupo de dezoito alunos pertences a $2^{\text {a }}$ série do ensino médio de uma escola católica particular de Santa Maria. A faixa etária dos alunos entrevistados era entre quinze e dezesseis anos, sendo sete dos entrevistados do sexo masculino e onze do sexo feminino.

Uma das perguntas do questionário tratava sobre a preferência de leitura dos alunos e os itens oferecidos para opção eram: leitura de ficção, não ficção, esotéricos, religiosos e auto-ajuda. Das onze meninas entrevistadas apenas 18,18\% optaram por leitura de ficção, 9,09\% por esotéricos, religiosos e auto-ajuda, e 72,72\% optaram por não-ficção. Dos sete meninos entrevistados, 14,28\% optaram por esotéricos, religiosos e auto-ajuda, 42,57\% optaram por ficção e 42,57\% por não-ficção.Como se pode perceber a maioria dos alunos optou por livros de não-ficção e somente $23,37 \%$ do total dos entrevistados optou por esotéricos, religiosos e de auto-ajuda, entretanto as perguntas que seguiam o questionário mostraram que muitos desses alunos que optaram pelo item não-ficção também lêem literatura que é classificada no meio literário de auto-ajuda.

Os alunos também foram questionados sobre a forma que buscavam resolver seus problemas e os itens de resposta oferecidos eram: conversa com amigos ou familiares, orações, pensamentos ou livros de auto-ajuda e outros. Dos sete meninos, $85,71 \%$ responderam que buscam solucionar seus problemas através de conversas com amigos ou familiares e apenas $14,28 \%$ respondeu que lê pensamentos ou livros de auto-ajuda. Das meninas entrevistadas $90,9 \%$ buscam solucionar seus problemas através de conversas com amigos e familiares e apenas 9,09\% optou por outras formas e acrescentou que busca conselhos. O que nos faz pensar que o público mais jovem precisa de aconselhamento através da troca de experiências, ou seja, uma 
forma mais interacionista, em que há uma troca entre sujeitos pertencentes a um mesmo grupo social e que partilham das mesmas idéias. Como o discurso de autoajuda é mais individualista, ou seja, trabalha muito com a questão do eu como um ser que tem condições de resolver-se sozinho (Rüdiger, 1995), percebeu-se através dos dados coletados no questionário que o adolescente em questão busca um discurso mais comunitário, um diálogo entre dois ou mais elementos pertences a um grupo.

O próximo item da pesquisa tratava sobre os autores preferidos deste público leitor e as opções apresentadas eram: Paulo Coelho, Brian Weiss, Rubem Fonseca e Letícia Wierzchowski. Dos sete meninos entrevistados, 57,14\% preferiram Paulo Coelho, 14,28\% preferiu Brian Weiss, 14,28\% não assinalou resposta e 14,28\% respondeu que nenhum dos escritores apresentados. Das onze meninas, $72,72 \%$ selecionaram Paulo Coelho, 9,09\% Brian Weiss, 9,09\% Letícia Wierzchowski e 9,09\% Rubem Fonseca. O que nos leva a concluir que em relação à literatura e leitura os adolescentes entrevistados têm por preferência os autores classificados como produtores de textos de auto-ajuda como Paulo Coelho e Brian Weiss, embora tenham respondido anteriormente que preferem ler livros classificados como não-ficção e não auto-ajuda e esotéricos como os destes escritores.

A pergunta que seguia a dos autores, era sobre títulos de livros que mais os atraiam, entre os títulos mencionados estavam: O diário de um mago, A Casa das Sete Mulheres, Diário de um Fescenino e A Semente da Vitória. Dos meninos entrevistados 57,14\% escolheram o título A Casa das Sete Mulheres, 14,28\% O diário de um mago, 14,28\% Diário de um Fescenino e 14,28\% não assinalou nenhuma das opções. Já das meninas que responderam o questionário 45,45\% optaram pelo livro A Semente da Vitória, 27,27\% pelo Diário de um mago e 27,27\% pela Casa das Sete Mulheres. A partir desde dado pode-se perceber que em relação à literatura os meninos preferem livros de ficção e as meninas na sua maioria preferem livros classificados como auto-ajuda e não-ficção.

O questionário também contemplava questões sobre a família, pois muito do que se observa no grupo escolar vem do que os alunos trazem de valores de seus lares e não só o que se aprende socializando na escola. A mesma pergunta a respeito da classificação dos livros lidos foi feita para os alunos a respeito dos pais. Dos meninos entrevistados $28,57 \%$ optaram pela literatura de ficção como a preferida dos pais, $57,14 \%$ pela literatura de não-ficção e $14,28 \%$ por esotéricos, religiosos e de 
auto-ajuda. Das meninas entrevistadas 45,45\% afirmam que os familiares lêem esotéricos, religiosos e de auto-ajuda e 54,54\% optaram pela literatura de não-ficção. Os dados nos levam a considerar que nas famílias dos meninos a literatura utilizada pelos pais reflete nas escolhas de seus filhos homens que por uma série de razões ideológicas talvez precisem menos deste tipo de literatura na visão de mundo dos pais, já a família das meninas em sua maioria lêem livros de auto-ajuda que também reflete na opção das meninas em relação à leitura, fazendo-nos pensar que por serem meninas, do sexo frágil, precisem de apoio e textos que reforcem as suas potencialidades dentro da sociedade.

Aos alunos também foi perguntado a respeito da sua visão sobre as pessoas que buscam a auto-ajuda, entre os itens para escolha da resposta, os alunos tinham: pessoas nervosas, auto-suficientes, esotéricas, em busca de sua identidade, e o item outros. Dos meninos entrevistados $42,85 \%$ selecionaram a opção sobre a busca da identidade, 28,57\% assinalou que as pessoas seriam nervosas, esotéricas, 14,28\% assinalou que seriam auto-suficientes e 14,28\% assinalou a opção outros e acrescentou que essas pessoas seriam seguidoras de moda. Das meninas entrevistadas $45,45 \%$ assinalaram que as pessoas estariam em busca da sua identidade, 18,18\% marcaram a opção outros e acrescentaram que são normais apenas inseguras e que buscam melhorar sempre, as seguintes alternativas tiveram apenas uma escolha cada (9.09\%): esotérica, auto-suficiente, nervosas e nenhuma opção.

O questionário também contemplava uma pergunta sobre o professor, sendo uma escola católica tendo como hábito escolar iniciar as aulas por uma oração, se o mesmo a fazia antes das aulas começarem e se esta oração ocasionava alguma mudança emocional. Todos os meninos e meninas responderam que sim, o professor faz orações antes das aulas começarem, 28,57\% dos meninos assinalou a opção que afirma que os mesmos sentiam-se motivados, $28,57 \%$ optaram pelo item outros e acrescentaram que se sentem mais fortes para alcançar os objetivos, ou que depende da ocasião, 28,57\% marcaram o item sem alteração do comportamento e 14,28\% escolheu bem disposto. Surpreendentemente 45,45\% das meninas optaram por sentirem-se normais, sem alteração do comportamento, 27,27\% dizem que se sentem mais calmas e outras $27,27 \%$ sentem-se motivadas. Estes dados nos levam a pensar que as orações feitas pelos professores em sala de aula não apresentam o efeito que 
o texto de auto-ajuda escrito por escritores profissionais possui. E que os meninos estariam mais propensos a se sensibilizarem pelo momento de oração em virtude do seu pouco contato com este tipo de texto e discurso por razões, algumas vezes, ideológicas e, também, pelo tipo de literatura que a família utiliza em casa. Já as meninas por terem um contato maior com este tipo de literatura são mais seletivas e exigentes quanto ao discurso de um leigo, que nosso caso é representado pelo professor.

O questionário termina com a pergunta aos alunos quanto à escolha de um tema para uma futura redação. Entre os temas ofertados estavam: biodiversidades, religião e comportamento, paz e segurança, economia e política. Dos meninos entrevistados 28,57\% selecionaram biodiversidades, $28,57 \%$ economia e política e $42,85 \%$ escolheram paz e segurança. Já das meninas $72,72 \%$ selecionaram paz e segurança, $18,18 \%$, religião e comportamento e $9,09 \%$ economia e política. Dos dados coletados podemos concluir que os meninos escolheram os temas relacionados aos textos lidos e já conhecidos bem como as meninas que pela pesquisa costumam ler mais sobre auto-ajuda e assuntos afins deste tema, escolhendo o tema paz e segurança na sua maioria.

\section{CONCLUSÃO}

Através da aplicação do questionário foi possível percebermos que os adolescentes partilham cada vez mais crenças com seus familiares e grupo de amigos, que, também, estão em busca de sua identidade e resolução de problemas e que para enfrentarem esses, vão ao encontro da família ou de amigos, pois através do contato face a face e do diálogo encontram respostas. A leitura praticada por estes jovens, em sua grande maioria do sexo feminino entre quinze e dezesseis anos de idade, pode ser classificada como de auto-ajuda, tanto pela escolha de seus autores preferidos quanto pelo título dos livros ofertados no questionário.

A diferença entre as opções feitas pelos membros do sexo feminino e masculino pode ser atribuída, talvez, pelos aspectos socioculturais que estes jovens tenham recebido de seus pais e educadores, fazendo com que os meninos busquem a literatura de não-ficção e as meninas, em sua maioria, o gênero auto-ajuda. 
Um dado interessante a respeito das opções feitas pelos entrevistados é em relação ao efeito comportamental após as orações realizadas em sala de aula, os meninos embora desapegados da auto-ajuda sentem-se mais motivados perante este tipo de discurso, já as meninas acostumadas ao tom argumentativo dos livros e até das falas de seus familiares, não mencionaram nenhuma alteração em seu estado emocional após as orações.

Também se pode cruzar os dados da pesquisa quanto à escolha dos temas de redação propostos no questionário, observou-se que aqueles que lêem e apreciam o gênero abordado neste artigo, preferem escrever sobre paz, segurança, religião e comportamento, já os que são voltados para a não-ficção, optaram por discorrer sobre biodiversidade, economia e política.

Desta forma pode-se perceber que o público-leitor adolescente do gênero autoajuda é em sua maioria feminino, e que as suas práticas de leitura estão relacionadas às demais atividades de produção textual bem como comportamentais e ideológicas.

\section{BIBLIOGRAFIA}

RÜDIGER, Ricardo Macedo. Literatura de Auto-Ajuda e Individualismo. Porto Alegre: UFRGS, 1995.

SMILE, Samuel. Self-Help. 1859. Disponível em:

<http://search.britannica.com/eb/article>. Acesso em: 9 de nov. 2003.

Van DIJK, T. Cognitive Discourse Analisis. 2002. Disponível em:

<http://www.Discourse-in-society.org >. Acesso em: 4 de nov. 2003. 


\section{ANEXO}

Responda o questionário de forma direta e objetiva.

1. Sexo: ( ) feminino ( ) masculino

2. Idade:

3. Série escolar:

4. Religião:

5. Preferência de leitura:

( ) Ficção ( ) Não-ficção （） Esotéricos, religiosos e auto-ajuda

6. Busca resolução de problemas através de:

( ) Conversa com amigos ou familiares

( ) Orações

( ) Pensamentos ou livros de auto-ajuda

( ) Outras formas:

7. Se pudesse escolher entre os seguintes autores, escolheria:

( ) Paulo Coelho

( ) Brian Weiss

( ) Rubem Fonseca

( ) Letícia Wierzchowski

8. Quais títulos de livros o atrairiam mais :
( ) O diário de um mago.
( ) A Casa das Sete Mulheres.
( ) Diário de um Fescenino.
( ) A Semente da Vitória.

9. Seus pais costumam ler livros classificados como:
( ) Fiç̧ão
( ) Não-ficção
( ) Esotéricos, religiosos e auto-ajuda 
10. As pessoas que buscam a auto-ajuda podem ser classificadas como:

( ) Nervosas

( ) Auto-suficientes

( ) Esotéricas

( ) Em busca da sua identidade

( ) outras:

11. Sua escola é:
( ) Católica
( ) Protestante
( ) Adventista
( ) Outra:

12. Seu professor faz orações antes de iniciar as aulas: ( ) sim ( ) não Caso a resposta seja positiva. Após a oração você se sente:
( ) Mais calmo
( ) Bem disposto
( ) Motivado

( ) Normal, sem alteração do comportamento ( ) Outros:

13. Em uma proposta de redação você escolheria o seguinte tema:

( ) Biodiversidades

( ) Paz e segurança
( ) Religião e comportamento

( ) Economia e política 